\title{
Some clinical aspects of pituitary-ovarian relationships in women with ovulatory infertility
}

\author{
I. D. Cooke, Elizabeth A. Lenton, M. Adams, Marianne A. Pearce, \\ Diana Fahmy* and C. R. Evans $\dagger$ \\ University Department of Obstetrics \& Gynaecology, \\ Jessop Hospital for Women, Sheffield S3 7RE, U.K.
}

\section{The defective luteal phase}

In the past 15 years the treatment of infertility has been affected most by progress in the induction of ovulation (Gemzell, Diczfalusy \& Tillinger, 1958; Lunenfeld, Menzi \& Volet, 1960; Kistner, 1975). The impact of this therapeutic advance is reflected in the diagnoses made during attendance at specialized clinics, as described by Cox (1975) and shown in Table 1, but there is still a large proportion of all patients ( $17.6 \%$ in Cox's study) in whom no cause can be found for their infertility.

Table 1. An analysis of causes of infertility in 900 couples (from Cox, 1975)

\begin{tabular}{lrr}
\hline \multicolumn{1}{c}{ Infertility factors } & No. & \multicolumn{1}{c}{$\%$} \\
\hline Male factors & 177 & $19 \cdot 7$ \\
Ovulatory failure & 386 & $42 \cdot 9$ \\
Tubal obstruction & 99 & $11 \cdot 0$ \\
None (apparently normal couple) & 158 & $17 \cdot 6$ \\
Other (menopausal, incomplete & 80 & $8 \cdot 9$ \\
$\quad$ investigations etc.) & & \\
\hline
\end{tabular}

Table 2. Causes of infertility and the corresponding pregnancy rate (both spontaneous and treated) in 114 infertile women with normal husbands

\begin{tabular}{lcc}
\hline \multicolumn{1}{c}{ Infertility factors } & $\begin{array}{c}\text { Incidence } \\
(\%)\end{array}$ & $\begin{array}{c}\text { Pregnancy rate } \\
(\%)\end{array}$ \\
\hline $\begin{array}{l}\text { Ovulatory failure } \\
\text { Organic (pelvic inflammatory }\end{array}$ & $47 \cdot 3$ & 44.5 \\
$\quad$ disease, endometriosis, & & \\
$\quad$ fibroids, etc.) & $15 \cdot 8$ & 22.2 \\
None (apparently normal couple) & $31 \cdot 5$ & 25.0 \\
Other (menopausal, etc.) & $5 \cdot 3$ & 0.0 \\
\hline
\end{tabular}

In our infertility clinic an analysis of 114 infertile women yielded diagnoses and pregnancy rates after 2 years' follow-up as shown in Table 2. Investigation of each couple consisted of seminal fluid analysis, tests of tubal patency and examination of basal temperature records, cervical mucus and endometrium to obtain information about the occurrence of ovulation. After the diagnosis and treatment of those patients with a specific barrier to conception, there was still a significant proportion of patients in whom there was no clear-cut anomaly. Basal temperature records of these patients, although biphasic, were very variable and often difficult to interpret (Lenton, Weston \& Cooke, 1977a). We rarely found the short luteal phases described by Strott, Cargille, Ross \& Lipsett (1970) and Sherman \& Korenman (1974), although slow rates of temperature rise following ovulation and irregularly maintained luteal phase elevations were quite common, particularly in those women

* Present address: Tenovus Institute for Cancer Research, Heath Park, Cardiff, U.K.

† Present address: Department of Obstetrics \& Gynaecology, Welsh National School of Medicine, Heath Park, Cardiff, U.K. 
without other obvious causes for their infertility. Defective luteal phases have been described by Jones (1949) as having one or more of the following features: histologically retarded endometrium, reduced excretion of urinary pregnanediol or abnormal temperature chart. Jones \& Pourmand (1962) found an incidence of $3.4 \%$ of this syndrome in 555 patients. We have used the term 'defective luteal phase' to apply to cycles of persistently infertile patients with recurrent biphasic basal temperature charts that seem to be abnormal in the luteal phase without necessarily having other stigmata of infertility. Using this as a primary selection criterion, we found an incidence that was much higher than that described by Jones \& Pourmand (1962) and this is represented in Table 2 as 'apparently normal couple'. These patients also sometimes had abnormal post-coital tests and retarded endometrium according to histological dating (Cooke, Morgan \& Parry, 1972), although neither of these was considered essential for the diagnosis.

The use of basal temperature records as a means of diagnosing patients with a defective luteal phase is, however, rather imprecise. In a recent study to test the accuracy of interpretation of basal temperature recordings in an infertility clinic, a group of gynaecologists was asked to evaluate 60 records from cycles in which the daily profiles of plasma $\mathrm{LH}, \mathrm{FSH}$, oestradiol and progesterone were known (Lenton et al., 1977a). Most of the women whose basal temperature records were used in this study were infertile without treatment although some were receiving treatment with clomiphene citrate and a small number of the charts were of conception cycles. Although $80 \%$ of the cycles were correctly classified as being either ovulatory or anovulatory, only $50 \%$ of the cycles were correctly classified as coming from a normal, pregnant or an infertile woman. Despite the difficulty of making an accurate diagnosis from the temperature chart alone, a temperature recording that shows a slow elevation after ovulation may be the only abnormality detectable in an otherwise apparently normal couple.

Table 3. Cumulative conception rate of spontaneous pregnancies in the 'apparently normal' infertile couple

\begin{tabular}{cccc}
\hline $\begin{array}{c}\text { Duration of infertility } \\
\text { (years) }\end{array}$ & Not pregnant & Pregnant & $\begin{array}{c}\text { Proportion } \\
\text { pregnant (\%) }\end{array}$ \\
\hline $2-3$ & 80 & 8 & $10 \cdot 0$ \\
$3-4$ & 71 & 9 & $21 \cdot 4$ \\
$4-5$ & 59 & 4 & $26 \cdot 5$ \\
$5-6$ & 55 & 4 & $31 \cdot 9$ \\
$6-7$ & 48 & 3 & $36 \cdot 2$ \\
$7-8$ & 37 & 4 & $43 \cdot 1$ \\
\hline
\end{tabular}

To ascertain whether patients complaining of infertility but in whom no abnormality could be found were 'normal', as they tended to be pronounced, or whether they really had persistent infertility, a long term follow-up study was undertaken (Lenton et al., 1977b). The clinical notes of a large number of patients who had been investigated for infertility at the Jessop Hospital for Women between 1967 and 1972 were reviewed. Ninety-six couples who had been thoroughly investigated and in whom no abnormality had been found were selected for follow-up. They were contacted by post and ultimately $71 \%$ were interviewed, although data were obtained from most of the 96 couples by return of the postal questionnaire. The length of the follow-up of these couples was from 1 to 17 years with $96 \%$ being followed until conception or for more than 5 years. Of those with primary infertility only $43 \%$ (as calculated by cumulative life table analysis) had conceived after 8 years of follow-up (Table 3), a surprisingly low pregnancy rate for a so-called 'normal' group. Lamb (1972) and Lamb \& Cruz (1972) have described a $65 \%$ pregnancy rate by life table analysis at 8 years follow-up for all their infertile patients in whom surgery and induction of ovulation with clomiphene were extensively used. It therefore seemed worthwhile and important to pursue the investigation of these patients who were considered to have no definable abnormality but who did have persistent sub-fertility. 


\section{Hormone concentrations}

Fifteen patients were selected on the basis of persistently abnormal basal temperature recordings and infertility (duration 2-7 years) despite regular, apparently ovulatory cycles. Daily blood samples were obtained in a total of 17 basal cycles and analysed for LH, FSH, oestradiol and progesterone concentrations by using the methods of Schalch, Parlow, Boon \& Reichlin (1968), Odell, Parlow, Cargille \& Ross (1968), England, Niswender \& Midgley (1974) and Morgan \& Cooke (1972) respectively. Similar daily blood samples were obtained from a group of 14 control subjects. These women all volunteered to give blood samples and although the majority were unmarried, and hence their real fertility was unknown, they all had regular ovulatory cycles (as assessed by biphasic temperature recordings over a 3-month period). The mean daily plasma concentrations of LH and FSH when pooled around the day of the LH peak did not reveal any marked differences between these two groups (Text-fig. 1a, b). Although mean plasma oestradiol levels were also very similar (Text-fig. 1c), small but significant differences were observed between the mean plasma progesterone profiles of the infertile women when these were compared with the control group (Text-fig. 1d). These differences were most marked during the early part of the luteal phase and were significant on Days $+1,+2$ and $+3(P<0.005)$ and on Days $+4,+5,+6$ and $+7(P<0.05)$.
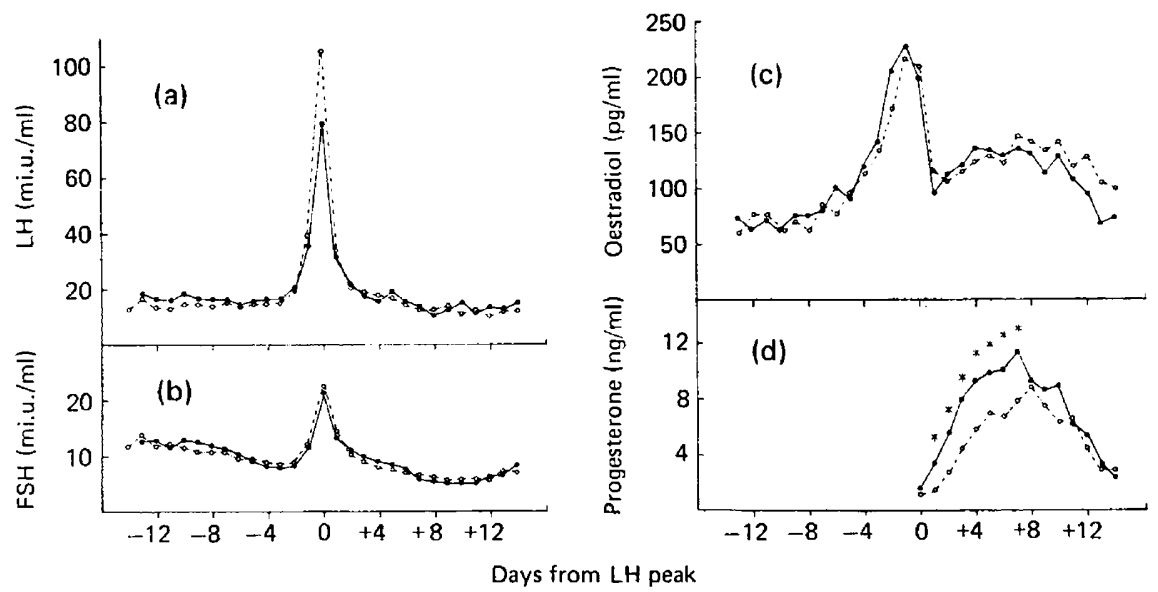

Text-fig. 1. Mean plasma concentrations of (a) LH, (b) FSH, (c) oestradiol and (d) progesterone in 17 cycles from a group of 15 infertile women $(O)$ compared with 16 cycles from 14 apparently normal control women ( ). Standard errors have been omitted from the figure for greater clarity. Where the differences between the mean are significant $(P<0.05)$, these have been indicated by an asterisk.

Although the mean plasma oestradiol concentrations were very similar, great variation was seen between individual patients in both groups (Text-fig. 2). Progesterone concentrations were less variable and, whatever the individual plasma oestradiol concentration, plasma progesterones tended to be lower in the infertile women than in the control group. The differences were, however, relatively small and it would be difficult to use individual hormone profiles on a diagnostic basis unless the progesterone defects were particularly severe, but provided the results from these persistently infertile patients were analysed as a group it was possible to obtain significant differences between them and a control group of women.

Of the four hormones measured, significant differences were only found in the plasma progesterone concentrations during the early luteal phase. We therefore felt that depression in progesterone secretion must be a major factor contributing to the persistent infertility in these women. These findings may also account for the high incidence of histologically retarded endometrium found in these patients (Cooke et al., 1972).

Reduced progesterone secretion indicates that the corpus luteum may not be functioning normally, perhaps due to an intrinsic defect in progesterone synthesis or to inadequate preparation of the 


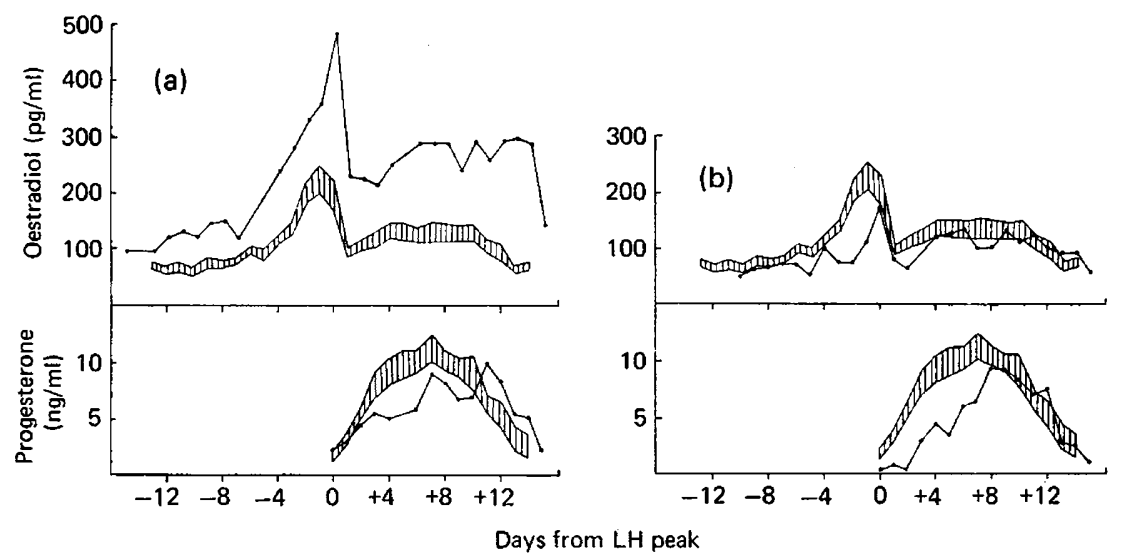

Text-fig. 2. Plasma oestradiol and progesterone concentrations throughout a cycle in (a) an infertile patient who had high levels of oestradiol in all cycles and (b) an infertile patient who generally had a low preovulatory oestradiol concentration. The cross-hatched area represents the mean \pm 1 S.E. of 16 normal control cycles.

granulosa cells during the preceding follicular phase. It would appear from Text-fig. 1 that the magnitude of the LH surge in these patients was completely normal, so it seems unlikely that luteinization was defective because of inadequate amounts of LH. The possibility still remains that the timing of the LH surge was in some way inappropriate, although this is difficult to reconcile with the apparently normal mean oestradiol profile (Text-fig. 1c). Follicular and luteal phase gonadotrophin concentrations were also within normal limits, suggesting that hypothalamic-pituitary function in these women was grossly normal and that the defect resulting in poor luteal function is restricted to the ovary.

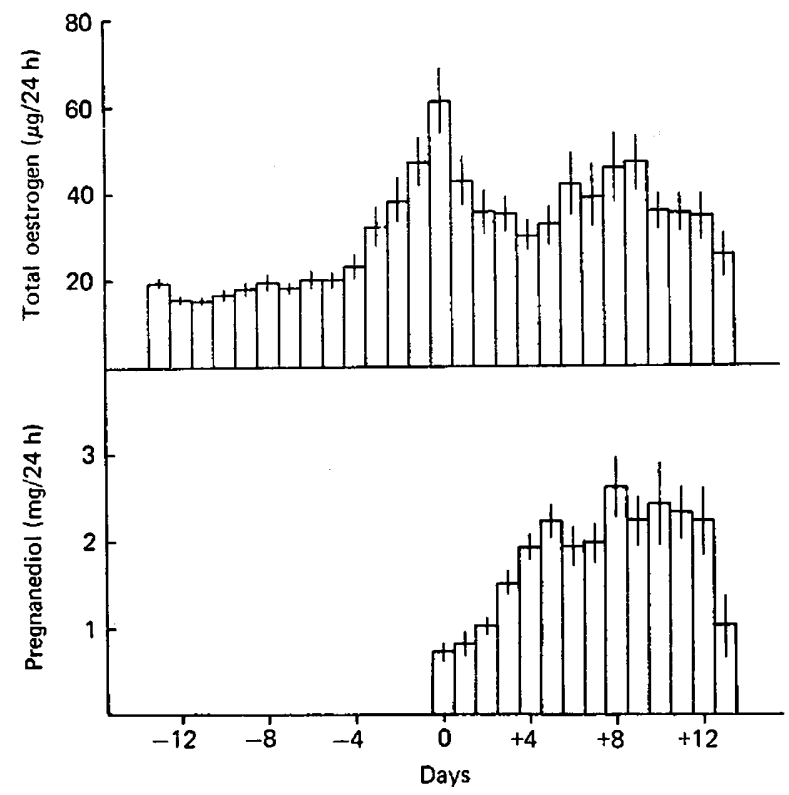

Text-fig. 3. Mean ( $₫$ S.E.M.) urinary total oestrogen and pregnanediol excretion in 17 basal cycles from 10 infertile women. 0 is the day of the total oestrogen peak. 


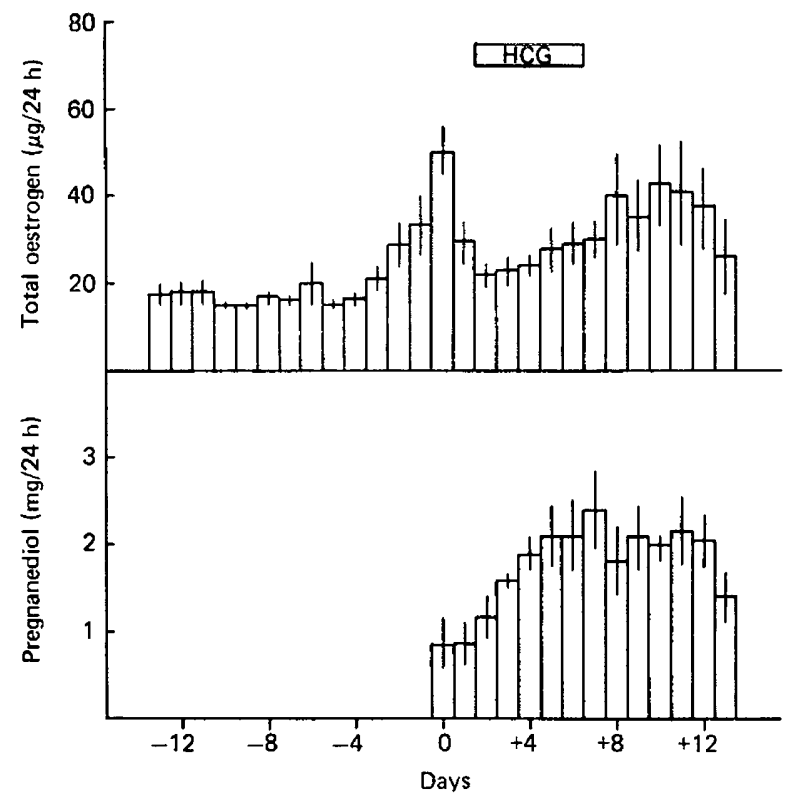

Text-fig. 4. Mean ( \pm S.E.M.) urinary total oestrogen and pregnanediol excretion in 8 cycles from 7 infertile women after three injections of HCG $(3 \times 6000$ i.u. $)$ during the early luteal phase of the cycle. 0 is the day of the total oestrogen peak.

\section{Exogenous gonadotrophin treatments}

To investigate further the nature of the defect, and at the same time to attempt treatment of patients, three different regimens of exogenous gonadotrophin were administered to another group of 10 infertile women. These patients had been selected by exactly the same criteria as enumerated above, i.e. persistent infertility (duration 2.5-15 years) and abnormal basal temperature recordings. A total of 17 basal cycles was monitored by daily 24-h urine collections (Text-fig. 3) which were analysed for total oestrogen by the method of Brown, MacLeod, Macnaughtan, Smith \& Smyth (1968) and

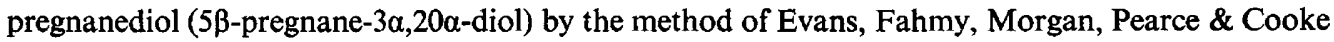
(1972). Unfortunately, 24-h urine collections were not obtained from a comparable series of normal women and it was therefore impossible to compare these results from infertile patients directly with those from normal women. The basal cycles in these 10 infertile patients, when pooled around the day of the total oestrogen peak (Corker, Michie, Hobson \& Parboosingh, 1976), showed essentially the same hormone profiles as the plasma samples (Text-fig. 1c, d). Mean oestrogen secretion was not obviously different from normal (Lenton \& Cooke, 1974), although again great individual variation was seen. The excretion of pregnanediol did, however, appear to be reduced when compared with normal mean values quoted in the literature (Lenton \& Cooke, 1974), and this depression was most apparent during the early part of the luteal phase.

Since both groups of infertile women described above showed the same defect, namely a decreased secretion of progesterone/pregnanediol excretion during the early luteal phase, the first treatment regimen that was attempted was direct luteal stimulation with HCG (Cooke, Pearce, Davies \& Campbell, 1973). Seven of the 10 patients were given three intramuscular injections of 6000 i.u. HCG each on alternate days during the first half of the luteal phase and again full 24-h urine collections were obtained and pooled around the total oestrogen peak. Preovulatory total oestrogen excretion in these cycles was, as expected, the same as that found in the basal cycles, but luteal oestrogen excretion after HCG administration was also unchanged (Text-fig. 4). In addition, no improvement in pregnanediol excretion occurred (Text-fig. 4), possibly because the corpora lutea in these patients, unlike those in normal women (Strott, Yoshimi, Ross \& Lipsett, 1969), were refractory to exogenous stimulation at this stage of the cycle. 
No further efforts to achieve direct luteal stimulation were made; instead indirect luteal stimulation was attempted by using intramuscular injections of HMG during the preceding mid-follicular phase. The rationale behind this regimen was an attempt to obtain greater follicular stimulation than that which normally occurred in these women in the expectation that this might lead to improved corpus luteum function. Since these patients normally ovulated spontaneously it was assumed that they would continue to do so after the administration of HMG. Three injections of HMG (at various dose levels) were given on alternate days (Butler, 1972) during the mid-follicular phase (generally on Days 6, 8 and 10), and again 24-h urine samples were collected.

The effects of exogenous stimulation on follicular development in these regularly ovulating women were not at all what we had anticipated. Twenty out of a total of 34 cycles monitored were abnormal to a greater or lesser extent. As far as it was possible without definite evidence about the presence of the LH surge in most of these cycles, they were grouped according to the type of abnormality found. When the day of the total oestrogen peak was used to predict the occurrence of the LH surge, confirmation was obtained from the pattern of pregnanediol excretion and in some cases by

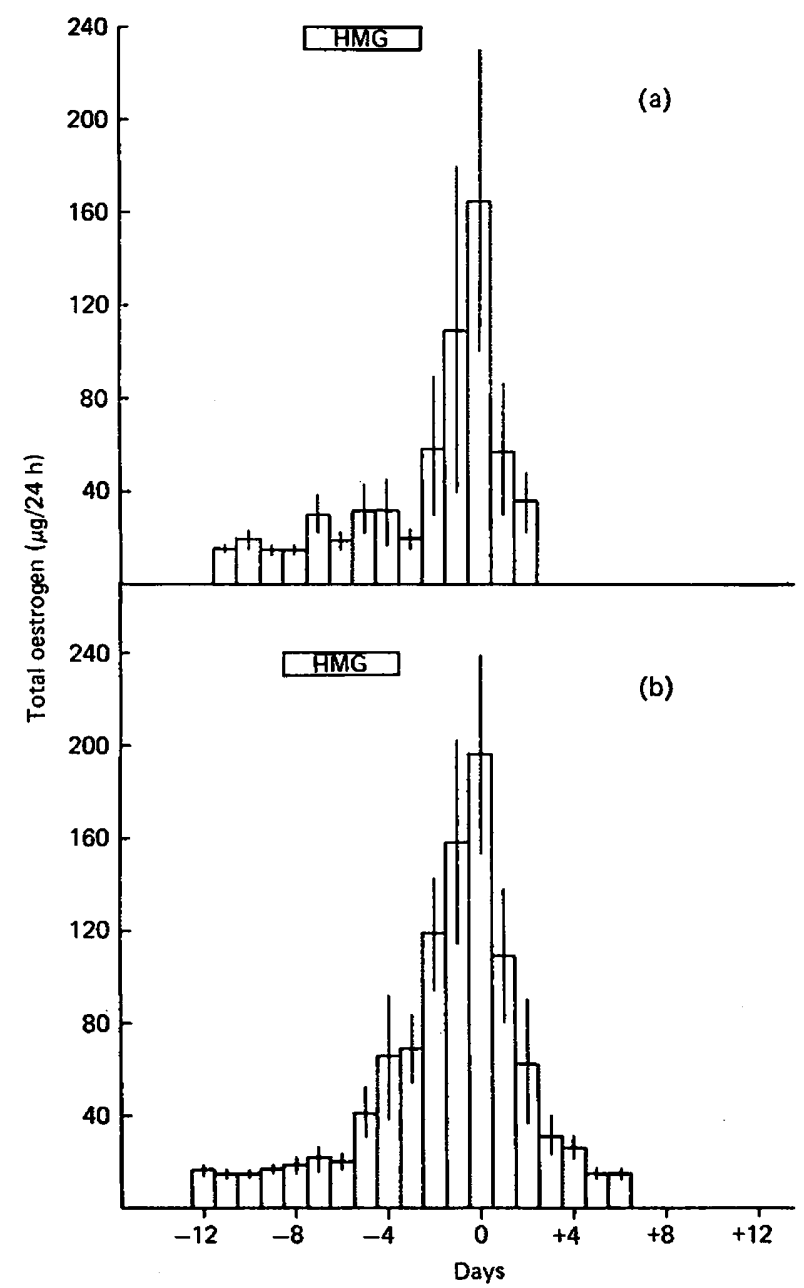

Text-fig. 5. Mean ( \pm S.E.M.) urinary total oestrogen excretion in cycles with an abnormal luteal phase after the administration of HMG in the mid-follicular phase. (a) Four aluteal cycles and (b) 5 cycles with short luteal phases (4-8 days). Pregnanediol excretion was absent in (a) and subnormal in (b). 0 is the day of the total oestrogen peak. 
Vabra biopsy. In four abnormally long cycles (11.8\%) it was considered that HMG had had no immediate effect on follicular maturation: the follicular phases were prolonged (21-23 days) but ovulation eventually occurred without further stimulation and was followed by luteal phases of normal length. A further four (11.8\%) very short cycles (of 13-16 days) were considered to be aluteal (Text-fig. 5). Despite an oestrogen response to HMG there was no evidence of ovulation or corpus luteum formation. Short luteal phases (defined as lasting less than 12 days from the total oestrogen peak to the onset of menses) (Abraham, Odell, Swerdloff \& Hopper, 1972) were seen in a further 12 $(35 \%)$ of the cycles. In five the luteal phase lasted from 4 to 8 days (Text-fig. 5) and in seven it was either 10 or 11 days in length. The remaining 14 cycles were all of normal length. Mean total oestrogen and pregnanediol excretion from 9 of them are shown in Text-fig. 6. Oestrogen secretion during the follicular phase was increased in all these cycles after HMG stimulation, although mean luteal oestrogen function was depressed to values below those found in the pretreatment (basal) cycles. Pregnanediol excretion was, if anything, slightly increased but the differences were small. There was one pregnancy following the injection of a total of 675 i.u. HMG. The steroid results from this cycle have been included in the data in Text-fig. 6 up until Day 23 of the cycle only.

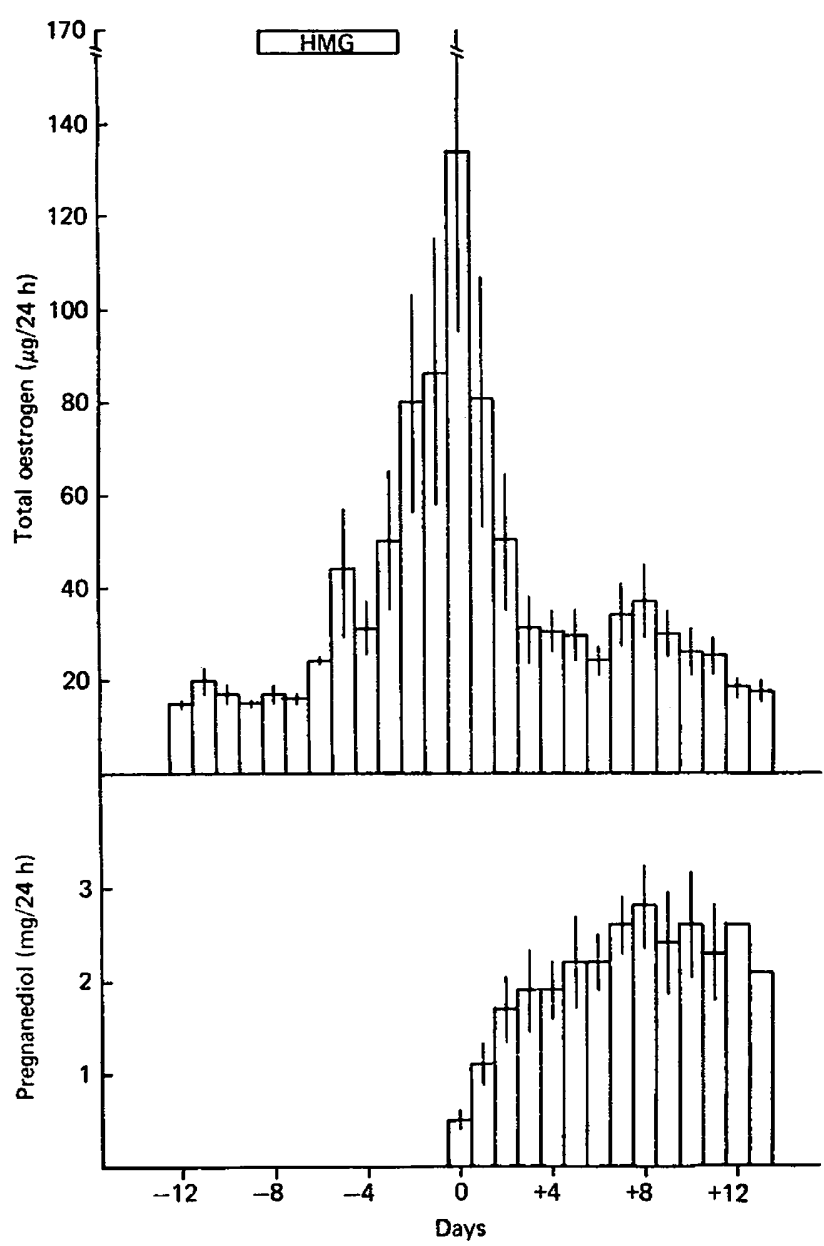

Text-fig. 6. Mean ( \pm S.E.M.) urinary total oestrogen and pregnanediol excretion in 9 cycles from 8 infertile women after the injection of various amounts of $H M G$ in the mid-follicular phase of the cycles. 0 is the day of the total oestrogen peak. 
Despite the slight improvement in pregnanediol excretion in the cycles of normal length, HMG treatment alone was not considered very successful because of the high percentage of abnormal cycles induced by it. For this reason a combined treatment regimen was adopted. The three mid-follicular phase HMG injections were followed by two HCG injections in the early luteal phase in a total of 40 cycles (Butler, 1972). Complete 24-h urine samples were analysed for oestrogen and pregnanediol in 12 cycles of the 9 patients, one having already conceived (Text-fig. 7). Total oestrogen excretion was greatly increased in both the preovulatory and luteal phases of the cycle and pregnanediol output was also improved, although there were no clinical signs of hyperstimulation. Three pregnancies occurred after treatment with total doses of 675, 900 and 1350 i.u. HMG.

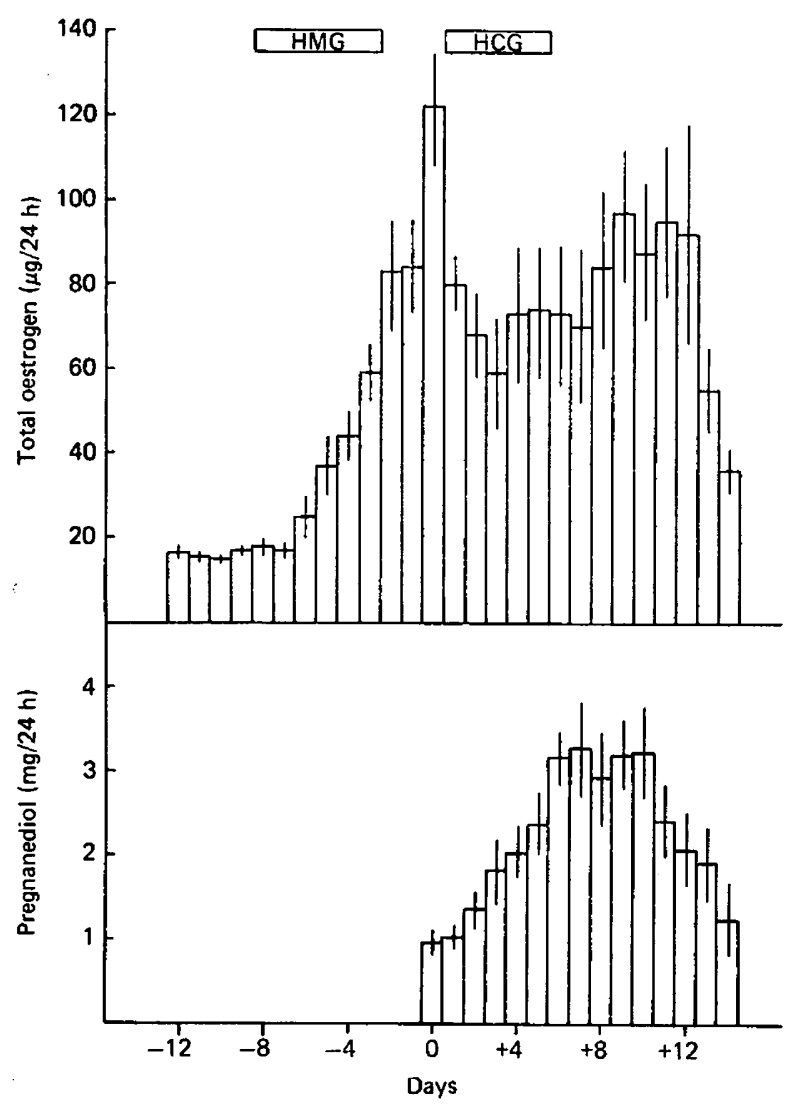

Text-fig. 7. Mean ( \pm S.E.M.) urinary total oestrogen and pregnanediol excretion in 12 cycles from 9 infertile women after three injections of HMG in the follicular phase followed by two injections of HCG in the early luteal phase. 0 is the day of the total oestrogen peak.

\section{Discussion}

It is surprising but not impossible that subtle alterations in either gonadotrophin or steroid secretion such as those described here could result in clinically normal but recurrently infertile cycles. Croxatto et al. (1976) have reported ovum recovery associated with normal endocrine profiles and it would be of great interest to know whether apparently minor alterations in steroid profile are associated with failure of ovum release. 
The endocrine profiles of the so-called normal cycles are also open to question. Few of our control subjects were married so their 'normality' can only be assumed, but, despite this, it seems most unlikely that more than one or at most, two of them might eventually experience difficulty in conceiving. However, an individual cycle can only be categorically said to be normal if it ends in conception. Daily blood samples which were obtained from a small number of cycles resulting in spontaneous conception and analysed for gonadotrophins and steroids (unpublished results) reflect the same wide variation in oestradiol concentrations. Plasma progesterone levels, however, fall within quite narrow limits that are very similar to those in our 'normal' control group but are greater than the progesterone levels found in our infertile patients.

Therapy directed specifically at stimulating corpus luteum function (HCG injections) has not been very successful in our hands, and we feel this may be because progesterone secretion is merely the result (and the only measurable defect found so far) of some abnormality of follicular development or function. Another reason could be the difficulty of timing the HCG injections in individual women and it is quite possible that a premature injection of HCG could itself produce a defective luteal phase. Follicular stimulation with HMG was most effective in raising the preovulatory oestrogen excretion, suggesting that the follicular FSH and LH receptors in these patients were quite normal. Luteal function, however, was frequently severely affected by this treatment, and even when the luteal phase was of normal duration pregnanediol excretion was not greatly increased. At this time we can only speculate on the disturbance of the normal menstrual rhythm produced by exogenous gonadotrophin in the follicular phase and presumably mediated through feedback control mechanisms.

The combined treatment regimen of HMG + HCG was effective in increasing oestrogen excretion in the follicular and luteal phases and to a lesser extent pregnanediol output. Preovulatory oestrogen excretion was of course similar to the levels seen in the HMG-only treatment cycles, but HCG administration in the early luteal phase prevented the decline in oestrogen excretion seen previously. It is of interest that luteal oestrogen excretion was increased to a much greater degree than pregnanediol excretion following HMG + HCG, which suggests that the exogenous gonadotrophin has stimulated a number of follicles, all of which are secreting oestradiol, but that only one follicle ruptures, and then luteinizes. Four pregnancies were achieved in these 10 patients, one following HMG only and the other three after HMG + HCG therapy. However, these pregnancies were only obtained after a total of $24 \mathrm{HMG}$ or $\mathrm{HMG}+\mathrm{HCG}$ treatment cycles in the 4 women, perhaps a reflection of the difficulties in successfully manipulating the cycles of patients who are ovulating spontaneously. Jayle, Palmer, Kamoun \& Matuchansky (1973) have also used an HMG + HCG regimen and although their clinical criteria are not well defined they have recorded a pregnancy rate of $12 \cdot 5 \%$.

The initial assumption that gonadotrophin secretion in these women was normal may have been a simplification. Although no difference in mean levels was detected, it is possible that qualitative alterations (Peckham, Yamaji, Dierschke \& Knobil, 1973) might be present (which would not necessarily be detectable by radioimmunoassay) or that aberrations exist in the feedback control mechanisms. It is also possible that prolactin may play a role in this disorder as McNatty, Sawers \& McNeilly (1974) have shown that prolactin reduced progesterone synthesis in vitro by granulosa cell cultures. Although Franks et al. (1975) have shown that bromocriptine administration can result in ovulation and pregnancy in amenorrhoeic hyperprolactinaemic women, there are no data to suggest that hyperprolactinaemia is a feature of patients with defective luteal phases. Preliminary empirical therapy with bromocriptine in our clinic has, however, resulted in a number of pregnancies in these regularly ovulating but infertile women.

In clinical reproductive physiology gross examples of disordered pituitary-ovarian relationship are clearly recognizable as amenorrhoea or anovulation. More subtle abnormalities may exist in women with apparently ovulatory menstrual cycles. If these women are persistently infertile, without diagnosable abnormality, small but important defects in the pituitary-ovarian axis must be considered. The results of the investigations of ovarian function described in this presentation lend support to the idea that abnormalities do exist. Closer study of this clinical situation could yield rewards in the greater understanding of pituitary-ovarian function. 
Part of this work was carried out at the Welsh National School of Medicine up to 1972, and part at the Jessop Hospital for Women, Sheffield. At Sheffield the work was supported by a grant from the Medical Research Council. We are indebted to all our fellow workers who assisted with the collection of samples and the analysis of the results and particularly to Miss L. Brook, Mrs L. Sexton and Mr C. Hughes of the Jessop Hospital, Sheffield, and to Miss R. Gardner, Miss J. Richards, Miss P. Welton, Mr G. Dyer and Miss B. Musselwhite of the Glossop Terrace Maternity Hospital, Cardiff, for expert technical assistance.

\section{References}

Abraham, G.E., Odell, W.D., Swerdloff, R.S. \& HOPPER, K. (1972) Simultaneous radioimmunoassay of FSH, LH, progesterone, 17-hydroxyprogesterone and estradiol-17 $\beta$ during the menstrual cycle. J. clin. Endocr. Metab. 34, 312-318.

Brown, J.B., Macleod, S.C., Macnaughtan, C., Sмiтн, M.A. \& SмYтH, B. (1968) A rapid method for estimating oestrogens in urine using a semi-automated estimation. J. Endocr. 42, 5-15.

BUTLER. J.K. (1972) Clinical results with human gonadotrophins in anovulation using two alternative dosage schemes. Postgrad. Med.J. 48, 23-32.

Cooke, I.D., Morgan, C.A. \& Parry, T.W. (1972) Correlation of endometrial biopsy and plasma progesterone in infertile women.J. Obstet. Gynaec. Br. Commonw. 79, 647-650.

Cooke, I.D., Pearce, M.A., Davies, K. \& Camprell, H. (1973) Results of treatments of infertile women with defective luteal phases by human menopausal gonadotrophin and human chorionic gonadotrophin. J. Reprod. Fert. 33, 355, Abstr.

Corker, C.S., Michie, E., Hobson, B. \& Parboosingh, J. (1976) Hormonal patterns in conceptual cycles and early pregnancy. Br. J. Obstet. Gynaec. 83, 489-494.

Cox, L.W. (1975) Infertility: a comprehensive programme. Br.J. Obstet. Gynaec. 82, 2-6.

Croxatto, H.B., Carril, M., Cheviakoff, S., Patriti, N., Pedroza, E., Croxatto, H.D., Gomez-Rogers, C. \& ROSNER, M. (1976) Time interval between $\mathrm{LH}$ peak and ovulation in women. In Biological and Clinical Aspects of Reproduction, pp. 282-284. Excerpta Medica, Amsterdam.

England, B.G., Niswender, G.D. \& Midgley, A.R. (1974) Radioimmunoassay of estradiol-17ß without chromatography.J. clin. Endocr. Metab. 38, 718-720.

Evans, C., Fahmy, D., Morgan, C.A., Pearce, M.A. \& COOKE, I.D. (1972) A method for urinary preg. nanediol determination using gas-liquid chromatography with electron capture. Clin. chim. Acta 38, 25-31.

Franks, S., Murray, M.A.F, Jequier, A.M., Steele, S.J., NABarRo, J.D.N. \& JACOBS, H.S. (1975) Incidence and significance of hyperprolactinaemia in women with amenorrhoea. Clin. Endocr. 4, 597603.

Gemzell, C.A., Diczfalusy, E. \& Tillinger, K.G. (1958) Clinical effect of human pituitary follicle stimulating hormone (FSH). J. clin. Endocr. Metab. 18, 1333-1348.

Jayle, M.F., PALMer, R., Kamoun, H. \& Matuchansky C. (1973) Le concept de l'insuffisance thecale du corps jaune humain, diagnostic et traitement. In $L e$ Corps Jaune, pp. 421-434. Eds R. Denamur \& A. Netter. Masson, Paris.

JoNEs, G.E.S. (1949) Some newer aspects of the management of infertility. J. Am. med. Ass. 141, 1123-1128.

JoNES, G.E.S. \& Pourmand, K. (1962) An evaluation of etiologic factors and therapy in 555 private patients with primary infertility. Fert. Steril. 13, 398-410.

KistNeR, R.W. (1975) Induction of ovulation with clomiphene citrate. In Progress in Infertility, pp. 509538. Eds S. J. Behrman \& R. W. Kistner. Little Brown \& Co., Boston.

LAMB, E.J. (1972) Prognosis for the infertile couple. Fert. Steril. 23, 310-319.

LAMB, E.J. \& CRUZ, A.L. (1972) Data collection and analysis in an infertility practice. Fert. Steril. 23, 310-319.

Lenton, E. \& CoOKE, I.D. (1974) Other disorders of ovulation. In Clinics in Obstetrics and Gynaecology, Vol. 1, pp. 313-344. Ed. I. D. Cooke. W. B. Saunders, London.

Lenton, E., Weston, G. \& CoOKe, I.D. (1977a) Problems in using basal body temperature recordings in an infertility clinic. Br. med. J. 1, 803-805.

Lenton, E., Weston, G. \& CoOKe, I.D. (1977b) Longterm follow-up of the apparently normal couple with a complaint of infertility. Fert. Steril. (in press).

Lunenfeld, B., Menzi, A. \& Volet, B. (1960) Clinical effects of human pituitary menopausal gonadotrophin. Acta endocr., Copenh. Suppl. 51, 587, Abstr.

McNatty, K.P., SAWers, R.S. \& McNeilly, A.S. (1974) A possible role for prolactin in control of steroid secretion by the human Graafian follicle. Nature, Lond. 240, 653-655.

Morgan, C.A. \& Cooke, I.D. (1972) A comparison of the competitive protein-binding assay and radioimmunoassay for plasma progesterone during the normal menstrual cycle. J. Endocr. 54, 445-456.

Odell, W.D., Parlow, A.F., Cargille, C.M. \& Ross, G.T. (1968) Radioimmunoassay for human follicle stimulating hormone; physiological studies $J$. clin. Invest. 47, $2551-2562$.

Peckham, W.D., Yamaji, T., Dierschke, D.J. \& KNOBIL, E. (1973) Gonadal function and the biological and physiochemical properties of follicle stimulating hormone. Endocrinology 92, 1660-1666.

Schalch, D.S., Parlow, A.F., Boon, R.C. \& Reichlin, S. (1968) Measurement of human luteinising hormone in plasma by radioimmunoassay. J. clin. Invest. $47,665-678$ 
Sherman, B.M. \& Korenman, S.G. (1974) Measurement of plasma LH, FSH, estradiol and progesterone in disorders of the human menstrual cycle. The short luteal phase. J. clin. Endocr. Metab. 38, 89-93.

Strott, C.A., Yoshim, T., Ross, G.T. \& LIPSETT, M.B. (1969) Ovarian physiology; relationship between plasma LH and steroidogenesis by the follicle and corpus luteum; effect of HCG. J. clin. Endocr. Metab. 29, $1157-1167$.

Strott, C.A., Cargille, C.M., Ross, G.T. \& LiPsetT, M.B. (1970) The short luteal phase. J. clin. Endocr. Metab. 30, 246-251. 